\title{
Diálogos entre uma Pedagogia Surda e o Ensino de Matemática
}

José Erliton Santos Santana

Salvador Cardoso Silva Muniz

Jurema Lindote Botelho Peixoto

\section{Resumo}

Este artigo apresenta uma pesquisa cujo objetivo foi identificar elementos da Pedagogia Surda que podem contribuir para uma Educação Matemática mais acessível para estudantes surdos na escola inclusiva. Assim, realizamos uma revisão bibliográfica usando os descritores "Pedagogia Surda", "surdez e educação", "surdez e Educação Matemática” para buscar trabalhos (livros, artigos científicos, teses e dissertações) no banco de dados da Coordenação de Aperfeiçoamento Pessoal de Nível Superior, no Google Acadêmico e no portal da Scielo, no período de 2004 a 2018. Os trabalhos foram lidos, analisados e catalogados em um quadro. O conceito da Pedagogia Surda destacou a identidade e a cultura surda produzida através da Língua de Sinais Brasileira e da concepção da surdez como uma experiência visual. Alguns dos trabalhos relativos ao ensino de Matemática, apesar de não citarem explicitamente o termo "Pedagogia Surda", apresentavam aspectos relevantes para promover uma Educação Matemática mais acessível, principalmente, porque expressavam as reivindicações dos próprios sujeitos. Os principais elementos identificados foram: a exploração da modalidade visual-espacial do sujeito surdo, a contextualização a partir de sua experiência sociocultural, a comunicação através da língua de sinais, subsídios que devem ser considerados na formação de professores e no planejamento da aula de Matemática para estudantes surdos.

Palavras-chave: Pedagogia Surda, Educação Matemática, Estudantes surdos. 


\title{
Dialogues between a Dedicated Pedagogy and the Teaching Of Mathematics
}

\author{
José Erliton Santos Santana \\ Salvador Cardoso Silva Muniz \\ Jurema Lindote Botelho Peixoto
}

Abstract

This paper presents a research whose objective was to identify elements of the Deaf Pedagogy that can contribute to a more accessible mathematics for the deaf subjects in the inclusive school. Thus, we carried out a bibliographic review using the descriptors " deaf Pedagogy ", "deafness and education", "deafness and Mathematics Education" to search for works (books, scientific articles, theses, and dissertations) in the database of the Coordination of Personal Improvement of Higher Level, in Google Scholar and Scielo, from 2004 to 2018. In this way, the works have been done read, analyzed and cataloged in the frame. The concept of Deaf Pedagogy highlighted the identity and deaf culture produced through the Brazilian Sign Language and the concept of deafness as a visual experience. Some of the works related to the teaching of mathematics, although they did not explicitly mention the term "Deaf Pedagogy ", presented important aspects to promote a Mathematical Education more accessible, mainly, because they expressed the claims of the subjects themselves. The main aspects identified for the teaching were: the exploration of the visual-spatial modality of the deaf subject, the contextualization from their socio-cultural experience, the communication through the sign language, subsidies that should be considered in the planning of a mathematics class for deaf students.

Key-Words: Deaf Pedagogy. Mathematics Education. Deaf students. 


\section{Introdução}

A surdez, definida por Lima (2006, p. 52) como "a perda total ou parcial, congênita ou adquirida, da capacidade de compreender a fala por intermédio do ouvido", sempre afetou muitas pessoas, sejam recém-nascidas, adultas ou idosas. Existe uma heterogeneidade de sujeitos surdos, dependendo do tipo de perda auditiva (de leve a profunda ${ }^{2}$ ) e do contexto sociocultural, em que estão inseridos, que impactam de forma diferente os seus processos cognitivos.

No Brasil, segundo o censo realizado em 2010 pelo Instituto Brasileiro de Geografia e Estatística - IBGE, cerca de 9,7 milhões de brasileiros possuem perda auditiva. Deste total, cerca de 2 milhões possuem perda severa (1,7 milhões têm grande dificuldade para ouvir e 344,2 mil são surdos), e 7,5 milhões apresentam alguma dificuldade auditiva. Entre esses, cerca de 1 milhão são crianças e jovens até 19 anos (ADAP, 2013).

Por muito tempo, os sujeitos surdos foram considerados ineducáveis, porquanto a perda auditiva comprometia seus processos comunicativos, consequentemente, cognitivos. Atualmente, a educação dos surdos é um tema que tem ocupado a agenda das pesquisas educacionais. Das várias abordagens adotadas ao longo do tempo, duas se sobressaem: o oralismo e o bilinguismo.

No oralismo, o intuito principal era desenvolver a oralidade do aluno surdo, incluindo-o nas comunidades ouvintes por meio da reabilitação da fala porque, somente assim, seriam considerados "normais". No apogeu da adoção da abordagem oralista, os surdos eram até impedidos de usar os sinais para a comunicação. Essa tentativa não foi bem aceita pela comunidade surda, pois foi considerada a forma institucionalizada do "ouvintismo", termo cunhado por Skliar (2005, p. 15) que significa, "um conjunto de representações dos ouvintes, a partir do qual o surdo está obrigado a olhar-se e a narrar-se como se fosse ouvinte". Essa elaboração crítica visa afastar a definição da surdez como patologia ou deficiência para aproximá-la do modelo de diferença cultural. Do ponto de vista do multiculturalismo, concordamos com o autor que cada cultura tem sua própria lógica, historicidade, processos de produção. Assim, mesmo integrando uma cultura dominante ouvinte, é possível enxergar aspectos de uma "cultura surda”. Karin Strobel (2008, p. 22), pesquisadora surda, define essa expressão como:

O jeito de o sujeito surdo entender o mundo e de modificá-lo a fim de tornálo acessível e habitável ajustando-os com as suas percepções visuais, que contribuem para a definição das identidades surdas e das 'almas' das

${ }^{2}$ Leve: de 20 a 50 dB. Moderada: de 50 a 70 dB. Severa: de 70 a 90 dB. Profunda: acima de $90 \mathrm{~dB}$. Geralmente ocorre diferenças entre os dois ouvidos (LIMA, 2006, p. 53). ISSN 2526-2882

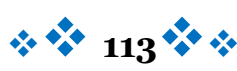


comunidades surdas. Isto significa que abrange a língua, as ideias, as crenças, os costumes e os hábitos de povo surdo.

O bilinguismo surge no seio dessas manifestações da comunidade surda em conjunto com pesquisadores ouvintes defensores dessa causa. O principal objetivo nessa abordagem é a utilização da Língua Brasileira de Sinais (Libras) como primeira língua (L1) e a Língua Portuguesa como segunda língua na modalidade escrita (L2). Na metodologia bilíngue, a Libras é considerada a língua natural do surdo, promove o seu desenvolvimento integral tanto nos aspectos linguísticos como cognitivos. A respeito do bilinguismo, Carneiro (2017) considera como sendo uma condição natural do surdo sinalizador.

Entendemos que a surdez não é uma "anormalidade", uma "deficiência", mas uma característica de um grupo específico que faz uso de uma língua própria para se comunicar, cuja modalidade é visual-espacial e não oral-auditiva, como a maioria da população.

Com o advento da inclusão, as escolas regulares recebem cada vez mais alunos surdos que antes eram atendidos apenas nas escolas de surdos ou especiais. Nesse sentido, a realidade dos alunos surdos em escolas regulares é muito complexa, uma vez que há alguns anos esses alunos frequentavam somente escolas especiais e, com o movimento da inclusão, muitos professores não estão preparados para planejar e desenvolver práticas que incluam, de fato, os alunos com surdez nas escolas regulares (MUNIZ, 2018).

O surdo, por sua vez, ainda não está obtendo um desempenho educacional satisfatório na proposta de educação inclusiva. Foi o que demonstrou a pesquisa de Capovilla (2011, p. 87): "estudantes surdos aprendem mais e melhor em escolas bilíngues (escolas especiais que ensinam em Libras e Português) do que em escolas monolíngues (escolas comuns que ensinam em Português apenas)”.

Com a Lei ${ }^{0} 10.436$ de 2002, a Língua Brasileira de Sinais (Libras) foi reconhecida como a língua oficial dos surdos. Posteriormente, o Decreto $\mathrm{n}^{0} 5 \cdot 626 / 2005$ inseriu a Libras como disciplina curricular obrigatória nos cursos de formação de professores para o exercício do magistério, em nível médio e superior, e para os cursos de Fonoaudiologia, nas instituições públicas e privadas. Também, garantiu a presença, em sala de aula, de um profissional Tradutor Intérprete da Língua de Sinais - TILS (Libras - Português), conforme Brasil (2002, 2005). Sem dúvida, a Lei e o Decreto foram conquistas importantes da comunidade surda, pois colaborou consideravelmente para a convivência dos surdos nas unidades escolares.

Nota-se também, que mesmo com a existência de alunos surdos dentro das salas de aula, as metodologias e planos de aulas ainda estão sendo formuladas, na maior parte das vezes, para alunos ouvintes, o que pode prejudicar o processo de aprendizagem dos alunos surdos. Essa suposição é verificada na pesquisa de Silva (2017), que apresenta indícios de ISSN 2526-2882

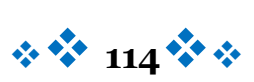


que as dificuldades enfrentadas pelos professores com alunos surdos nas escolas regulares retardam o processo de ensino e aprendizagem de Matemática e também na pesquisa de Muniz (2018), na qual percebeu-se que as professoras de Matemática não utilizavam nenhuma metodologia específica para o trabalho pedagógico com os estudantes surdos.

A surdez não indica, imediatamente, déficit cognitivo, mas as dificuldades de aprendizagem dos surdos podem ser decorrentes do isolamento comunicativo causado pela surdez (NUNES, 2004; LACERDA, 2006). Assim, existe a falta de trocas semânticas significativas, a partir da Libras, entre os profissionais envolvidos no processo de ensino/aprendizagem e os estudantes surdos. Nesse sentido, a Lei Brasileira da Inclusão LBI (BRASIL, 2015), ratifica que a deficiência não está no sujeito, mas na incapacidade da sociedade de lidar com as diferenças humanas.

Neste contexto, surge um termo que tem aparecido em alguns trabalhos de pesquisadores surdos e tem chamado nossa atenção, a "Pedagogia Surda". Mas, o que significa essa pedagogia?

A Pedagogia Surda foi um termo cunhado pelos próprios surdos. Segundo Silva (2012, p. 267), essa pedagogia caracteriza-se como "uma nova perspectiva de educação bilíngue que evoca a língua de sinais e que surge a partir dos próprios surdos por meios de movimentos de resistência" que se impõem contra o padrão dominante ouvinte na educação de surdos. Corroborando com isso, Stumpf (2008, p. 26) defende que, para avançar na qualidade de educação é preciso "desenvolver um trabalho enfocando a questão das representações sobre os surdos e a questão da identidade, construindo uma Pedagogia Surda que apresenta a surdez como uma experiência visual". Para Perlin e Strobel (2008), uma Pedagogia Surda denota: o respeito pela diferença surda, valorização da sua cultura e sua identidade, trazendo a experiência visual como uma perspectiva a ser explorada no ensino e aprendizagem, além da incessante luta pela utilização da língua de sinais nos espaços escolares. Essa proposta retrata o anseio por uma maior representatividade cultural dos surdos no contexto educacional, ou seja, uma maior participação dos próprios surdos, dos intérpretes, instrutores ${ }^{3}$ surdos, ou seja, dos membros da cultura surda nas decisões políticas educacionais.

Neste estudo, o objetivo foi identificar elementos da Pedagogia Surda que podem contribuir para uma educação matemática mais acessível para estudantes surdos na escola inclusiva. Para responder a esta questão, desenvolvemos uma revisão de literatura que será explicitada na próxima seção.

3 São professores de Libras, de preferência surdos (Decreto $\mathrm{n}^{0} 5.626$ ), que atuam no Atendimento Educacional Especializado nas escolas comuns, no turno oposto (BRASIL, 2011). ISSN 2526-2882 


\section{A Revisão de Literatura}

Para responder a questão de pesquisa e atender ao objetivo proposto empreendemos uma pesquisa exploratória e essencialmente bibliográfica.

Dessa forma, buscamos trabalhos ou pesquisas (artigos científicos, livros, dissertações e teses) nas bases de dados da CAPES, no Google Acadêmico e no portal da Scielo, no período de 2004 a 2018, utilizando os seguintes descritores: "Pedagogia Surda", "surdez e Educação Matemática”, "Educação e surdez".

No primeiro levantamento, nos resumos, observamos os seguintes aspectos: a) identificação do artigo (periódico, ano, volume, páginas, título, área, autores, palavraschave); b) presença dos descritores (no título, no resumo, nas palavras-chave, no corpo do texto); c) pertinência (se possui aspectos relevantes para o campo de ensino/aprendizagem de surdos). Considerando o critério "c", selecionamos 18 trabalhos para serem discutidos nesse texto, sendo cinco do portal CAPES, sete da biblioteca eletrônica Scielo e seis do Google acadêmico. Em seguida, sistematizamos esses resultados em um quadro, classificando os trabalhos em: monografia, artigo, dissertação e tese (Quadro 1). 
Quadro 1 - Trabalhos selecionados segundo as categorias: Tese, Dissertação, Artigo e Monografia.

\begin{tabular}{|c|c|}
\hline Categoria & \\
\hline Tese & $\begin{array}{l}\text { SALES, E. R. A visualização no ensino de matemática: uma } \\
\text { experiência com alunos surdos. } 2013 \text {. }\end{array}$ \\
\hline Tese & $\begin{array}{l}\text { PEIXOTO, J. L. B. Análise dos esquemas de surdos sinalizadores } \\
\text { associados aos significados da divisão. } 2015 \mathrm{~b} \text {. }\end{array}$ \\
\hline Dissertação & $\begin{array}{l}\text { NEVES, M. J. B. A Comunicação em matemática na sala de aula: } \\
\text { obstáculos de natureza metodológica na educação de alunos surdos. } 2011 .\end{array}$ \\
\hline $\mathrm{Di}$ & $\begin{array}{l}\text { LEITE, M. D. Design da interação de interfaces educativas para o } \\
\text { ensino de matemática para crianças e jovens surdos. } 2007\end{array}$ \\
\hline ação & $\begin{array}{l}\text { BARROS, D. D. Formação inicial de professores de matemática na } \\
\text { perspectiva da educação inclusiva: contribuições da disciplina de } \\
\text { LIBRAS. 2017. }\end{array}$ \\
\hline Disse & $\begin{array}{l}\text { CARNEIRO, F. H. F. O ensino da matemática para alunos surdos } \\
\text { bilíngues: uma análise a partir das teorizações de Michel Foucault e Ludwig } \\
\text { Wittgenstein. } 2017 \text {. }\end{array}$ \\
\hline Artigo & $\begin{array}{l}\text { FÁVERO, M.H; PIMENTA, M. L. Pensamento e Linguagem: A Língua } \\
\text { de Sinais na Resolução de Problemas. } 2006 .\end{array}$ \\
\hline Artigo & $\begin{array}{l}\text { SALES, E. R; PENTEADO, M. G; MOURA, A. Q. A negociação de sinais } \\
\text { em LIBRAS como possibilidade de ensino e aprendizagem de } \\
\text { geometria. 2015. }\end{array}$ \\
\hline Artigo & $\begin{array}{l}\text { STREIECHEN, E. M; LEMKE, C. K; OLIVEIRA, J. P; CRUZ, G. C. Pedagogia } \\
\text { Surda e bilinguismo: pontos e contrapontos na perspectiva de uma } \\
\text { educação inclusiva. 2017. }\end{array}$ \\
\hline Artigo & $\begin{array}{l}\text { IXOTO, J. L. B. A pesquisa com alunos surdos no projeto teias: } \\
\text { ntexto, desafios e perspectivas. } 2010 .\end{array}$ \\
\hline $\mathrm{Al}$ & $\begin{array}{l}\text { REIECHEN, E. M; LEMKE, C. K. Análise da produ } \\
\text { rdos alfabetizados com proposta bilíngue: implicac } \\
\text { dagógica. } 2014 \text {. }\end{array}$ \\
\hline $\mathrm{Ar}$ & $\begin{array}{l}\text { JEIROZ, T. V de; LAUTERT, S. Que fatores } \\
\text { problemas de multiplicação por crianc } \\
\text { portes de representação? 2014. }\end{array}$ \\
\hline $\mathrm{Al}$ & $\begin{array}{l}\text { ARBOSA, H. H. Conceitos matemáticos iniciais e linguagem: um } \\
\text { tudo comparativo entre crianças surdas e ouvintes. } 2014 \text {. }\end{array}$ \\
\hline Artigo & $\begin{array}{l}\text { CAMPELHO, A. R.; REZENDE, P. L. F. Em defesa da escola bilíngue } \\
\text { para surdos: a história de lutas do movimento surdo brasileiro. } 2014 \text {. }\end{array}$ \\
\hline Artigo & $\begin{array}{l}\text { STROBEL, K. L. A visão histórica da in(ex)clusão dos surdos nas } \\
\text { escolas. } 2006 \text {. }\end{array}$ \\
\hline Artigo & $\begin{array}{l}\text { PEIXOTO, J. L. B. Gestos, sinais e esquemas de aprendizes surdos na } \\
\text { multiplicação. 2015a. }\end{array}$ \\
\hline Artigo & $\begin{array}{l}\text { MIRANDA, C. J. A.; MIRANDA, T. L. O Ensino de } \\
\text { Surdos: Quais os Desafios que o Professor Enfrenta? } 2\end{array}$ \\
\hline Mono & $\begin{array}{l}\text { SILVA, J. S. F. O processo do ensino de matemática para alunos } \\
\text { surdos: uma investigação com professores de escolas públicas do município } \\
\text { de Sertânia - PE. } 2017 \text {. }\end{array}$ \\
\hline
\end{tabular}

$$
\text { Produção dos autores }
$$

Durante a leitura desses trabalhos, buscando identificar as respostas inquiridas, foi possível elencar duas categorias para desenvolvermos uma análise interpretativa dialogada, quais sejam: 1. Educação de surdos: rumo a uma Pedagogia Surda; 2. Ensino/aprendizagem de Matemática para surdos. Salientamos que nessa análise, o "diálogo" será considerado

$$
\text { ISSN 2526-2882 }
$$


como "um método de conversação que busca [...] a produção de percepções e idéias novas" (MARIOTTI, 2001, p.1).

\section{Educação de surdos: rumo a uma Pedagogia Surda}

A educação de surdos passou por várias fases. Na antiguidade, os surdos eram marginalizados na família e na sociedade. A partir da idade moderna, período em que a educação formal era para poucos, surgem propostas de médicos e pedagogos que investiram no potencial desses sujeitos. Segundo Streiechen et al. (2017, p. 93):

Há algumas décadas, as pessoas surdas precisavam passar por uma reabilitação em que seus resíduos auditivos eram estimulados com intuito de ouvirem determinados sons e, assim, pudessem desenvolver a oralidade. Acreditava-se que, dessa forma, os surdos estariam 'preparados' para serem inseridos na sociedade [...] o surdo viveu períodos críticos e dolorosos, nos quais muitos educadores e profissionais tentaram, a todo custo, transformálos em ouvintes.

Nesse período, a deficiência era definida pela medicina, isto é, do "modelo médico". Nessa concepção, a pessoa surda precisa ser oralizada ou curada através de recursos adaptados (aparelhos auditivos e, recentemente, o implante coclear) para participar da sociedade e ter acesso aos seus benefícios. Essa concepção, enraizada socialmente, ainda promove a exclusão de sujeitos quando não responsabiliza a sociedade sobre o seu papel (STROBEL, 2006).

Hoje, a LBI (BRASIL, 2015), fruto de diversas conquistas das pessoas com deficiência, apresenta o modelo social da deficiência que salienta a responsabilidade e papel da sociedade na inclusão educacional de todos. Nessa lei a pessoa com deficiência é "aquela que tem impedimento de longo prazo de natureza física, mental, intelectual ou sensorial, o qual, em interação com uma ou mais barreiras, pode obstruir sua participação plena e efetiva na sociedade em igualdade de condições com as demais pessoas" (BRASIL, 2015, p.01).

Assim, não cabe apenas a esta pessoa "adaptar-se” à sociedade, mas a sociedade precisa assumir o seu papel no agenciamento da inclusão social e educacional, promovendo recursos, técnicas, metodologias, aportes teóricos e pedagógicos para tal fim.

O movimento da inclusão escolar teve início na década de 90, desse modo, as escolas comuns passaram a receber diversos estudantes com deficiência, inclusive estudantes surdos. Mas, para a pesquisadora surda Strobel (2006, p. 246), a educação inclusiva "é um fato imposto em muitos países, inclusive no Brasil; entretanto, historicamente, veremos que tem havido fracasso na educação de surdos". Segundo a autora, muito surdos concluem o ensino médio sem saber escrever. Segundo a autora, às práticas pedagógicas "ouvintistas”, ou seja, que tomam como referência o padrão ouvinte são a causa desse fracasso. Portanto, a prática ISSN 2526-2882 
pedagógica precisa considerar que os surdos "possuem uma identidade lingüística e cultural que os diferencia dos outros” (p. 251).

O padrão ouvinte na sala de aula pode ser percebido, por exemplo, quando o professor usa vídeos que não tem acessibilidade em Libras, vira de costas para o surdo na aula, fica apenas copiando no quadro ou não privilegia recursos visuais. Dessa forma, Strobel (2006, p. 252), recomenda para a proposta de inclusão nas escolas ouvintes que:

As mesmas se preparem para dar aos alunos surdos os conteúdos pela língua de sinais, através de recursos visuais, tais como figuras, língua portuguesa escrita e leitura, a fim de desenvolver nos alunos a memória visual e o hábito de leitura; que recebam apoio de professor especialista conhecedor de língua de sinais e enfim, proporcionando intérpretes de língua de sinais, para o maior acompanhamento das aulas. Outra possibilidade é contar com a ajuda de professores, instrutores e monitores surdos, que auxiliem o professor e trabalhem com a língua de sinais nas escolas.

Nesse sentido, a formação de professores para o atendimento de surdos "depende da convivência com a comunidade surda, a aprendizagem da língua de sinais e o estudo de uma pedagogia ampla” (SKLIAR, 1998 apud STROBEL, 2006, p. 252).

Campello e Rezende (2014) narram a trajetória histórica do Movimento Surdo em defesa das Escolas Bilíngues para Surdos. Essa defesa baseia-se no Decreto $n^{\circ} 5.626$ de 22/12/2005, que regulamenta a Lei $\mathrm{n}^{\mathrm{0}}$ 10.436/2002, em seu capítulo VI, artigo 22, determina para a inclusão escolar que se organize:

I - escolas e classes de educação bilíngue, abertas a alunos surdos e ouvintes, com professores bilíngues, na educação infantil e nos anos iniciais do ensino fundamental;

II - escolas bilíngues ou escolas comuns da rede regular de ensino, abertas a alunos surdos e ouvintes, para os anos finais do ensino fundamental, ensino médio ou educação profissional, com docentes de diferentes áreas do conhecimento, cientes da singularidade lingüística dos alunos surdos, bem como a presença de tradutores e intérpretes de Libras - Língua Portuguesa.

Nas escolas bilíngues, abertas para surdos e ouvintes, a primeira língua de acesso ao conhecimento científico e veiculada no espaço escolar é a Libras. Portanto, frente à ameaça da extinção do Instituto Nacional de Educação de Surdos, em 2011, a comunidade surda organizou-se para uma mobilização visando à inclusão das Escolas Bilíngues para Surdos no Plano Nacional de Educação - PNE (sancionado pela Lei 13.005/2014). O alvo desse movimento, ainda em curso, é lutar:

Por uma Política Nacional de Educação Bilíngue condizente para a formação da Identidade Linguística da Comunidade Surda, garantida pela Convenção Internacional sobre Direitos das Pessoas com Deficiência, que reconhece a 
importância da Língua de Sinais e da Cultura Surda para as Pessoas Surdas (CAMPELLO; REZENDE, 2014, p. 71).

A comunidade surda defende a manutenção de escolas bilíngues, pois os resultados da proposta de inclusão educacional para os surdos não têm sido satisfatórios. Os argumentos para essa defesa baseiam-se na proposição que uma criança surda precisa de um compartilhamento linguístico para adquirir a Libras espontaneamente, assim como a criança ouvinte adquire a língua oral no seio da sua família. Na carta aberta ao ministro da educação em 2012 (CAMPELLO; REZENDE, 2014, p. 83), a comunidade explica:

O fato de os alunos surdos estudarem em Escolas Bilíngues, onde são considerados e aceitos como uma minoria linguística, não significa segregar. A Libras é a primeira língua da maioria dos surdos brasileiros e não uma língua falada apenas por pessoas "deficientes". [...] A postura segregadora não parte de nós, mas dos que não aceitam nossas especificidades e necessidades.

Uma das necessidades prementes da pessoa surda é o letramento na Língua Portuguesa, sua segunda língua, pois a surdez limita esse aprendizado que pode ser mediado pela Libras, sua língua natural. Nesse contexto, Streiechen e Lemke (2014) analisaram a produção escrita de surdos alfabetizados na proposta bilíngue com o objetivo de refletir sobre o processo de escrita de alunos surdos e apontar possíveis implicações para as práticas pedagógicas em ambientes inclusivos. Participaram do estudo sete alunos com surdez profunda bilateral ${ }^{4}$ que iniciaram atendimento educacional, com idades por volta de dois e quatro anos. O autor destaca que os professores precisam considerar que: o domínio da escrita pelo surdo passa primeiro pela aprendizagem da língua de sinais, sua primeira língua; copiar textos apenas não garante o aprendizado; a influência dos aspectos sintáticos da Libras na avaliação dos textos dos surdos, pois os estudantes escrevem na forma que sinalizam essa língua; "a presença do professor bilíngue e do tradutor/intérprete de Libras em sala de aula é fundamental para que o aluno surdo tenha acesso efetivo a todos os conteúdos, desde que o aluno apresente fluência na língua de sinais" (p. 983).

Nesses trabalhos, destaca-se a importância do uso da Libras nas atividades pedagógicas na escola bem como no desenvolvimento do letramento na Língua Portuguesa. O sujeito surdo é membro de uma comunidade surda de minoria linguística que tem uma cultura própria, caracterizada pela sua experiência visual e linguística. Dessa forma, o surdo tem que ser um sujeito bilíngue, educado preferencialmente em escolas bilíngues e essa abordagem deve ser assumida também na escola inclusiva com a presença dos intérpretes,

4 Da mesma faixa etária, mas o artigo não especifica nem a idade nem a série do aluno. ISSN 2526-2882

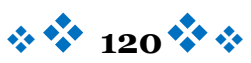


viabilizada pelo uso de recursos visuais e materiais bilíngues. Consideramos que esses aspectos apontam para uma Pedagogia Surda.

\section{Ensino e aprendizagem de matemática para surdos}

A partir da década de 70, a pesquisa educacional focava o desempenho de estudantes surdos em Matemática, sejam crianças ou jovens, sempre comparando com os ouvintes na mesma faixa etária (LEITE, 2007). A autora ainda apresenta várias pesquisas que mostram um baixo desempenho matemático de estudantes surdos em comparação com ouvintes, e que apontam como uma das causas à falta de experiências informais com a matemática no cotidiano:

A perda auditiva limita muitas fontes de informação (por exemplo, rádio, conversas ao redor da mesa de jantar) e, assim, a aprendizagem informal pode apresentar lacunas. Como consequência alguns conceitos abstraídos implicitamente em período anterior ao escolar podem precisar de um reforço, um exemplo é a composição aditiva, que explora que a compreensão de qualquer número pode ser vista como a soma de outros números, conceito este que pode ser aprendido em experiências com dinheiro (LEITE, 2007, p. 28).

A dissertação de Leite (2007) buscou aspectos para enriquecer as experiências cognitivas do aluno surdo na resolução de problemas através de uma interface computacional. Usando uma metodologia centrada no usuário, a autora apresentou o design de uma interface que explorou problemas aditivos. Os resultados mostraram que o uso da Libras e da língua portuguesa na forma escrita, dos ícones representativos em Libras, das formas de ajuda e mensagens de feedback relacionadas com a situação-problema, das variadas formas de representação do campo aditivo, da disponibilidade de formas de ajuda alternativa, entre outras coisas, contribuíram para a interação e aquisição do conhecimento pelo usuário surdo.

Para tentar compreender o baixo desempenho de surdos em Matemática, Barbosa (2014) investigou o desenvolvimento matemático de crianças ouvintes e surdas (que usam a língua de sinais). Participaram da pesquisa 43 crianças, sendo 11 surdas e 32 ouvintes, de idade entre 5 e 6 anos (educação infantil, escolas públicas e privadas) por meio de tarefas experimentais que compreendam vários aspectos cognitivos ligados à conceituação quantitativo-numérica. Segundo a autora, os resultados sugerem que:

Crianças surdas têm o mesmo desempenho ou, em alguns casos, até mesmo um desempenho superior do que crianças ouvintes em habilidades menos dependentes do estímulo linguístico. Contudo, tanto as crianças surdas quanto as crianças ouvintes mais jovens da escola pública demonstraram um desempenho significativamente baixo em relação às crianças ouvintes mais ISSN 2526-2882

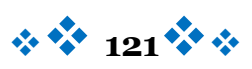


velhas da escola pública e às crianças da escola privada. Tal resultado indica que a surdez não é causa de baixo rendimento escolar na área da Matemática. Assim, parece ser necessário pensar em formas de intervenção pedagógica que possam garantir uma aprendizagem de sucesso em Matemática tanto para as crianças surdas, quanto para as crianças ouvintes que frequentam as escolas públicas brasileiras (BARBOSA, 2014, p. 163).

Considerando a negociação de significados em Libras, a pesquisa de doutorado de Sales (2013), investigou como os alunos surdos se desenvolvem em atividades que privilegiam os aspectos visuais. Para isso, desenvolveu uma intervenção abordando conceitos geométricos, numa escola pública do ensino regular, com oito alunos surdos do $4^{\circ}$ ano do Ensino Fundamental, para observar como os alunos surdos se desenvolvem durante essas atividades, tendo a Libras como a língua de instrução. A pesquisa concluiu que a visualidade do surdo não é algo natural, precisa ser desenvolvida. Os resultados reforçaram a importância da Libras na apropriação e negociação de significados e "de se estreitar a relação entre universidade e escola, o desenvolvimento de uma colaboração mútua em prol da aprendizagem de crianças surdas e seus benefícios para os que nela se envolveram” ( p. 8).

O autor apresenta um recorte dessa pesquisa em um artigo cujo objetivo foi discutir a negociação de sinais em Libras, em aulas de Matemática, utilizando os diálogos cujo tema foi Geometria. Os resultados mostraram:

A importância do processo de negociação de sinais para a ampliação da Libras no campo lexical, bem como para o envolvimento dos alunos na atividade uma vez que oferece uma oportunidade de exploração das propriedades matemáticas envolvidas nas tarefas. Por fim, reconhece-se que a inclusão de estudantes com deficiência na escola regular parece estar bem amparada pela legislação em relação ao acesso, mas ainda é preciso mais ações que garantam espaços de aprendizagem para todos (SALES; PENTEADO; MOURA, 2015, 1268).

Essa exploração de sinais para ampliação da Libras e, consequentemente, do ensino de Matemática para surdos, é um dos pontos para garantir o aprendizado desses sujeitos. Sobre a comunicação matemática, a dissertação de Neves (2011), teve o objetivo de "analisar as diferentes maneiras pelas quais professores ouvintes e surdos interpretam e traduzem para a Língua de Sinais e para a Linguagem matemática - problemas matemáticos, de estruturas multiplicativas, elaborados em Língua Portuguesa” (p. 16). Participaram desta pesquisa oito estudantes surdos, dois professores fluentes em Libras com graduação em Matemática, sendo um deles surdo, e uma professora especialista em Educação Especial. Dentre os resultados destacam-se:

O professor precisa conhecer a forma de pensar do sujeito surdo, e isto incorre diretamente no domínio da linguagem deste sujeito. Sendo 
conhecedor profundo da Língua deste sujeito, este profissional tem perfeitas condições de fazer a interpretação/tradução do conhecimento matemático para a Língua Materna dos surdos. O que nossos dados nos informam está de acordo com nossa hipótese, de que o melhor professor para o aluno surdo é aquele que consegue transitar entre as três linguagens necessárias à compreensão matemática do surdo [...]. Nossa pesquisa revela que o domínio da tríade, conhecimento matemático, LIBRAS e Língua Portuguesa se faz fundamental para o ensino desse educando. A falta de domínio de uma dessas três áreas de conhecimento tem como consequência obstáculos metodológicos, contribuindo para a concretização de obstáculos de aprendizagem (NEVES, 2011, p. 108- 109).

No tocante da formação de professores de Matemática, é urgente que os cursos de Licenciatura em Matemática, promovam maiores discussões no âmbito da inclusão de surdos e da Libras. Entendendo a importância desse fator na formação inicial de professores de Matemática, a dissertação de Barros (2017, p. 8) teve como objetivo "compreender quais os aspectos de uma disciplina de Libras que poderiam "contribuir para a formação de egressos de um curso de Licenciatura em Matemática, no que diz respeito a Educação Matemática na perspectiva da inclusão”. Assim, realizou um estudo de caso sobre uma disciplina de uma universidade pública do estado de São Paulo, analisou o programa da disciplina e fez entrevistas semiestruturadas com docentes (2) e egressos (12) para conhecer e discutir suas contribuições na formação destes profissionais. Concluiu que essa disciplina foi relevante para o debate da Educação Inclusiva na formação inicial possibilitando aos estudantes "um novo olhar para as diferenças", podendo "favorecer o planejamento de atividades em uma perspectiva inclusiva e o contato com o básico da Libras, conhecendo caminhos que podem oportunizar estudos futuros" (BARROS, 2017, p. 8).

Quanto aos olhares de professores já formados, foi destacado também a necessidade da Libras e de como a ausência dessa língua contribui para a dificuldade no ensino de Matemática. Silva (2017) analisou as percepções de três professores sobre o ensino de Matemática para alunos surdos em escolas públicas na cidade de Sertânia/PE. As professoras responderam a um questionário composto por nove perguntas. $\mathrm{O}$ autor destacou que existem ainda muitos desafios para o professor: "Muitas vezes, o professor não tem condições de atender adequadamente o aluno surdo que se encontra em uma sala de aula junto a aproximadamente quarenta alunos ouvintes" (p. 20). Portanto, destaca a necessidade desse professor ser proficiente em Libras para ensinar o surdo, pois precisam "falar próximo ao aluno e usar uma linguagem clara para que ele possa entender o conteúdo” (p. 20).

Nessa mesma perspectiva, o artigo de Miranda e Miranda (2011), apresenta uma reflexão sobre o ensino da Matemática para surdos, destacando a necessidade do conhecimento da cultura surda para compreensão das "singularidades dessas pessoas" na aquisição de conhecimento matemático. Para isso, enfatiza a importância do professor 
entender a sintaxe da Libras "para se chegar ao raciocínio lógico-matemático do aluno, bem como a sua alfabetização e letramento matemático" (p. 31).

A Libras, enquanto língua oficial dos Surdos, poderá trazer os significados reais do que é ensinado. Entender que a Libras favorece negociação dos conceitos Matemáticos para surdos é imprescindível para um melhor desenvolvimento destes conceitos. Assim, Fávero e Pimenta (2006) investigaram a resolução de problemas matemáticos, com surdos entre 18 e 33 anos, os resultados mostraram que a dificuldade dos surdos nesses problemas estão relacionados com o processo de escolarização, que prioriza "procedimentos de resolução, em detrimento da aquisição conceitual e pelo uso inadequado da Libras, como instrumento para a organização de significados semióticos e aquisição de conhecimentos” (p. 225). Para essas autoras, o ensino de Matemática deve priorizar "a contextualização de fatos numéricos, permitindo a negociação de significados matemáticos de modo a favorecer a negociação de conceitos” (p. 235), o que só é possível por meio dos recursos da linguagem e da Libras.

Queiroz e Lautert (2014, p. 8) investigaram 88 alunos de escolas públicas, sendo 44 surdos e 44 ouvintes, para verificar como as formas de "apresentação dos problemas matemáticos (em Português, na Interlíngua 5 ou em Libras, esses últimos só para os surdos) e os suportes de representação disponibilizados (material concreto definido, lápis e papel e representação visual)" podiam influenciar o desempenho dos alunos surdos, antes e depois da instrução formal sobre a multiplicação (22 alunos de cada grupo receberam esta instrução). De forma geral, os dados apontaram que a escrita no português favoreceu ouvintes e a escrita na Interlíngua e a interlocução em Libras favoreceu surdos. Quanto ao efeito dos suportes de representação, eles "interferiram no desempenho juntamente com a forma escrita dos problemas", principalmente "nas tarefas em que o grupo teve dificuldade em relação à escrita". As autoras recomendam "aproximar a forma de apresentação dos enunciados matemáticos à realidade dos surdos" e "pensar em rotas alternativas de ensino, em salas de aula inclusivas, para aquisição de conceitos matemáticos por surdos (p. 8).

Em se tratando de problemas matemáticos, Peixoto (2010) avaliou o desempenho em problemas aditivos de três jovens estudantes com surdez bilateral severa (de 22, 24 e 19 anos do $6^{\circ}, 7^{\circ}$ anos do Ensino Fundamental e $1^{\circ}$ ano do Ensino Médio). Em relação às competências de cálculo, envolvidas nas operações fundamentais (adição, subtração, multiplicação e divisão), os sujeitos dominavam muito pouco os algoritmos escolares, principalmente a adição com reserva, a subtração com recurso e a divisão. Esses sujeitos também não demonstraram estratégias mais elaboradas de cálculo mental, oriundas da vida extraescolar. Identificar a operação a ser feita, só foi possível com as intervenções em Libras,

5 Escrita dos surdos nos anos iniciais, sem alguns elementos na construção de frases como artigos, desvios de flexão de tempo e modos verbais. 
com ajudas visuais, com outros contextos de compra e venda relacionados ao cotidiano do aluno.

A partir dessa pesquisa, a autora buscou identificar esquemas mobilizados por esses três alunos surdos usuários da Libras no cálculo da multiplicação, utilizando o conceito de esquema de Gérard Vergnaud e da tipologia dos gestos de David McNeill. As tarefas analisadas mostraram que todos os alunos apresentaram o esquema de correspondência sinal-a-sinal ou sinal-a-dedo coordenado com a contagem, e dois alunos apresentaram o procedimento de contar. A partir de seus esquemas articularam, simultaneamente, sinais com gestos, porém os gestos extrapolaram a função da comunicação e passaram a integrar a ação cognitiva desses alunos (PEIXOTO, 2015a).

$\mathrm{Na}$ sua tese de doutorado, entrevistou professores, TILS e alunos surdos sinalizadores matriculados no ensino médio (13 estudantes) para conhecer suas dificuldades em Matemática. Em seguida, selecionou cinco estudantes do ensino médio (quatro do $1^{0}$ ano, de 18 anos e uma do $2^{\circ}$ ano, de 24 anos) para analisar os esquemas e as ações viso-gestuaissomáticas em Libras, no contexto de resolução de problemas associados aos significados da divisão, mostrando a importância da análise do discurso em Libras e dos gestos que acompanham esta língua para a comunicação matemática (PEIXOTO, 2015b). Como consequência, a autora recomenda para uma atividade de resolução de problemas:

O TILS ou o próprio professor de Matemática deve sinalizar com clareza e devagar os dados numéricos do problema. Deve-se ter cuidado com o contexto criado em Libras para transmitir a informação, pois pode ajudar muito, mas também pode atrapalhar, transformando o problema em outro problema. O excesso de elementos nas representações visuais pode atrapalhar e tirar a atenção dos estudantes. Se for necessário utilizar esses recursos, deve-se focar no essencial para ajudar a memória. Os problemas podem conter ilustrações concisas e estilizadas dos elementos relacionais. Assim, o professor precisa fazer as escolhas dos recursos visuais dependendo do contexto da situação e de cada estudante. No caso de utilizar apenas a Libras, o TILS ou o professor pode sugerir aos estudantes que anotem, no quadro ou caderno, os dados numéricos (PEIXOTO, 2015, p. 219).

Carneiro (2017) desenvolveu uma análise do discurso de enunciados produzidos nas narrativas de quatro professoras dos Anos Iniciais do Ensino Fundamental sobre uma escola bilíngue para alunos surdos e o ensino de Matemática. O autor (p. 9) afirma que:

[...] tanto a escola de surdos como a de ouvintes se ocupam da produção de sujeitos disciplinados, normalizados a partir de um modelo a ser seguido, contudo, no caso dessa primeira, com um referencial de normalidade pautado em saberes provenientes da comunidade surda. Na disciplina de Matemática, especificamente, foi identificado que as semelhanças de família entre o ensino de surdos e ouvintes é ainda mais forte, visto que este campo de conhecimento, segundo os dados empíricos, pode ser trabalhado 
visualmente. Percebeu-se que a imperatividade do uso dos materiais concretos nas aulas de Matemática também está presente, porém com uma outra justificativa: a de que o aluno surdo é um sujeito visual.

Em síntese, observamos nesses trabalhos alguns aspectos da aprendizagem de surdos que o professor de Matemática deve atentar na prática da sala de aula. Por exemplo, o ensino dessa disciplina precisa contemplar as características da Libras, enquanto língua espacial-visual capaz de promover a compreensão matemática através da negociação de significados. A visualidade do surdo, como aponta Sales (2013), precisa ser explorada. Assim, não basta usar recursos visuais sem uma compreensão do papel desses na atividade matemática, pois o excesso deles pode até prejudicar a atenção do estudante surdo (PEIXOTO, 2015). Além disso, foi possível observar também que, a formação de professores de Matemática é um ponto que merece destaque, tendo em vista as dificuldades que os professores possuem em se comunicar com esse público. Talvez, essa dificuldade seja consequência da falta de investimentos em discussões sobre educação inclusiva e surdez na formação inicial do professor.

Investir na formação e conseguir uma maior discussão em termos da cultura surda fará com que os professores, ainda em formação inicial, entendam as particularidades desse estudante, as diferenças de uma língua na modalidade visual-espacial e busquem desenvolver práticas de ensino visando construir possibilidades de aprendizagem.

\section{Considerações finais}

Nesse estudo foi possível notar que, apesar de avanços, ainda existe muito a ser desenvolvido para que a inclusão de surdos, de fato, se concretize. As políticas públicas sustentam a inclusão desses estudantes, preferencialmente, em escolas comuns, mas também apoiam as escolas especiais, entretanto é preciso investir em uma política linguística bilíngue de forma mais efetiva, como defende a comunidade surda. A Libras poderia constar no currículo das escolas comuns e não apenas na universidade como aponta o Decreto $\mathrm{n}^{\mathrm{o}}$ 5.626/2005, pois beneficiaria os estudantes surdos na escola inclusiva.

No ensino de Matemática, verificou-se a necessidade de práticas de ensino mais adequadas para esses sujeitos. Por outro lado, observou-se também um avanço nas pesquisas, que outrora mediam o desempenho de estudantes surdos baseado no padrão ouvinte, agora investigam os surdos a partir de suas especificidades.

Essas pesquisas trazem ricas contribuições para melhorar a prática de ensino de Matemática na escola. Nesse processo, entra em cena o papel fundamental do professor e/ou pedagogo, uma vez que ele é, juntamente com os aprendizes surdos, o protagonista do ensino de Matemática para esses sujeitos. 
Mas é preciso compreender que o sujeito surdo não é "deficiente", nem necessita ser "normalizado" para ser educado, como aponta a visão de deficiência ancorada no modelo médico, em que a surdez é vista como doença que precisa ser curada. Ficou bem claro que a comunidade surda anseia por uma educação de qualidade que considere as especificidades dos surdos, seja em escolas bilíngues ou em escolas inclusivas. Por isso, reivindica uma "Pedagogia Surda", compreendendo que o sujeito, alvo dessa pedagogia, é outro, tem uma cultura, é naturalmente educável e requer novas abordagens educacionais voltadas para suas características linguísticas.

A concepção de uma Pedagogia Surda não é ainda unanimidade em todos os ambientes escolares, mas foi possível notar indícios dessa concepção nas pesquisas e, por conseguinte, no processo educacional nas instituições de ensino em que existem estudantes surdos. Enfim, destacamos os elementos de uma Pedagogia Surda que podem corroborar para o ensino e a aprendizagem de Matemática: (i) a exploração da modalidade visualespacial, ou seja, da experiência visual do surdo; (ii) a contextualização nas situações de ensino e aprendizagem, buscando exemplos ou problemas que considere a identidade e a cultura surda; (iii) a comunicação em Libras visando aperfeiçoar a negociação dos significados matemáticos e (iv) a consideração da proposta bilíngue em todas as atividades na sala de aula.

Por fim, esse conjunto de elementos, identificados nos trabalhos citados, apresentou a concepção de Pedagogia Surda e seus aspectos principais que, em nossa opinião, podem integrar uma Educação Matemática mais acessível, principalmente, porque expressam as reivindicações dos próprios sujeitos. Esses aspectos precisam ser levados em conta na formação de professores e no planejamento de uma aula de Matemática para estudantes surdos.

Nesse contexto, ensinar Matemática no contexto inclusivo torna-se uma atividade mais complexa, pois o professor deve valorizar as especificidades de todos os estudantes e utilizá-las na sua prática, para que esses estudantes se sintam parte da aula e não um peso durante a mesma. Desse modo, a formação inicial de professores de Matemática, precisa assumir a responsabilidade de levantar mais concretamente as discussões da educação inclusiva.

\section{Referências}

ADAP. Associação de Deficientes Auditivos, Pais, Amigos e Usuários de Implante Coclear, 2013. Disponível em: 
<http://www.adap.org.br/site/index.php/artigos/20-deficiencia-auditiva-atinge-97-milhoes-de-brasileiros>. Acesso em: 28 jul. 2016.

BARBOSA, H. H. Conceitos matemáticos iniciais e linguagem: um estudo comparativo entre crianças surdas e ouvintes. Educação e Pesquisa. São Paulo, v. 40, n. 1, 2014.

BARROS, D. D. Formação inicial de professores de matemática na perspectiva da educação inclusiva: contribuições da disciplina de LIBRAS. 2017. 110f. Dissertação (Mestrado em educação matemática) - Instituto de Geociências e Ciências Exatas, Universidade Estadual Paulista, Rio Claro, 2017.

BRASIL. Lei $\mathrm{n}^{\circ}$ 10.436, 24 de abril de 2002. Dispõe sobre a Língua Brasileira de Sinais Libras e dá outras providências. Presidência da República, Casa Civil, Subchefia para Assuntos Jurídicos, Brasília, DF, 2002. Disponível em:<http://www.planalto.gov.br/ccivil_03/leis/2002/L10436.htm>. Acesso em: 11 fev. 2016.

. Decreto 7611, de 17 de novembro de 2011. Revoga o Decreto no 6.571, de 17 de setembro de 2008. Dispõe sobre a educação especial, o atendimento educacional especializado e dá outras providências. Presidência da República, Casa Civil, Subchefia para Assuntos Jurídicos, Brasília, DF: 2011. Disponível em: <http://www.planalto.gov.br/ccivil_03/_ato2011-2014/2011/decreto/d7611.htm>. Acesso em: 07 jul. 2015.

. Lei Brasileira da Inclusão n. 13.146, de o6 de Julho de 2015. Presidência da República, Casa Civil, Subchefia para Assuntos Jurídicos. Brasília, DF, 2015. Disponível em: < http://www.planalto.gov.br/ccivil_03/_Ato20152018/2015/Lei/L13146.htm>. Acesso em: 16 mar. 2015.

. Decreto $\mathrm{n}^{0} 5.626$, de 22 de dezembro de 2005. Regulamenta a Lei $\mathrm{n}^{0} 10.436$, de 24 de abril de 2002, e o art. 18 da Lei $\mathrm{n}^{\mathrm{o}}$ 10.098, de 19 de dezembro de 2000. Presidência da República, Casa Civil, Subchefia para Assuntos Jurídicos, Brasília, DF: 2000. Disponível em: $<$ http://www.planalto.gov.br/ccivil_03/Ato20042006/2005/Decreto/D5626.htm>. Acesso em: 12 de set. de 2010.

CAMPELLO, A. R.; REZENDE, P. L. F. Em defesa da escola bilíngue para surdos: a história de lutas do movimento surdo brasileiro. Curitiba, PR: Editora UFPR.

CAPOVILLA, F. C. Sobre a falácia de tratar as crianças ouvintes como se fossem surdas, e assurdas, como se fossem ouvintes ou deficientes auditivas: pelo reconhecimento do status linguístico especial da população escolar surda. In: SÁ, N. de. Surdos: qual escola? Manaus: Valer e Edua, 2011. p. 77-100. 
CARNEIRO, F. H. F. O ensino da matemática para alunos surdos bilíngues: uma análise a partir das teorizações de Michel Foucault e Ludwig Wittgenstein. 2017. 156f. Dissertação (Mestrado em educação) - Programa de Pós-Graduação em Educação, Universidade Federal do Rio Grande do Sul, Porto Alegre, 2017.

FÁVERO, M.H; PIMENTA, M. L. Pensamento e Linguagem: A Língua de Sinais na Resolução de Problemas. Universidade de Brasília, Brasília, 2006.

LACERDA, C. B. F. de. A inclusão escolar de alunos surdos: o que dizem alunos, professores e intérpretes sobre esta experiência. Cad. CEDES. v. 26, n. 69, 2006, p. 163-184.

LEITE, M. D. Design da interação de interfaces educativas para o ensino de matemática para crianças e jovens surdos. 2007. 149 f. Dissertação (Mestrado em Ciência da Computação) - Centro de Informática, Universidade Federal de Pernambuco, Recife, 2007.

LIMA, P. A. Educação Inclusiva e Igualdade Social. São Paulo: Avercamp, 2006.

lioteca/artigos/dialogo-um-metodo-de-reflexao-conjunta/>. Acesso em: 27 set. 2013

MARIOTTI, Humberto. Diálogo: um método de reflexão conjunta e observação compartilhada da experiência. Revista Thot, v. 76, p. 6-22, 2001. Disponível em:< http://escoladedialogo.com.br/escoladedialogo/index.php/bib

MIRANDA, C. J. A.; MIRANDA, T. L. O Ensino de Matemática para Alunos Surdos: Quais os Desafios que o Professor Enfrenta?. Revista Eletrônica de Educação Matemática. Florianópolis, v. 06, n. 1, p. 31-46, 2011.

MUNIZ, S. C. A inclusão de surdos nas aulas de Matemática: uma análise das relações pedagógicas envolvidas na tríade professora - Intérprete - surdo 2018. $118 f$. Dissertação (Mestrado em Educação Matemática), Universidade Estadual de Santa Cruz, Ilhéus, 2018.

NEVES, M. J. B. A comunicação em matemática na sala de aula: obstáculos de natureza metodológica na educação de alunos surdos. 2011. 131 f. Dissertação (Mestrado em Educação em Ciências e Matemáticas) - Instituto em Educação Matemática e Científica, Universidade Federal do Pará, Belém, 2011.

NUNES, T. O ensino de matemática para crianças surdas. 2004. Disponível em: <http://www.education.ox.ac.uk/ndcs/papers/oensinodematematicanunes2004.pd f>. Acesso em: 23 set. 2013.

PEIXOTO, J. L. B. A pesquisa com alunos surdos no projeto teias: contexto, desafios e perspectivas. 2010. Disponível em: <http://www.lematec.net.br/CDS/ENEM10/artigos/MR/MR15_Peixoto.pdf >. Acesso em 12 jun. 2015 . 
QUEIROZ, T. V; LAUTERT, S. L. Que fatores interferem na resolução de problemas de multiplicação por crianças surdas: a língua ou os suportes de representação? JIEEM, São Paulo, v.7, n. 2, 2014.

- Gestos, sinais e esquemas de aprendizes surdos na multiplicação. Revista Latinoamericana de Investigación em Matemática Educativa- Relime, México, v. 18, n. 3, p. 1-28, novembro 2015a.

- Análise dos esquemas de surdos sinalizadores associados aos significados da divisão. 2015b. 266 f. Tese (Doutorado em Difusão do Conhecimento) - Faculdade de Educação, Universidade Federal da Bahia, Salvador, 2015b.

PERLIN, G. T. T; STROBEL, K. L. Fundamentos da educação de surdos. Florianópolis, SC: UFSC, 2008.

SALES, E. R.A visualização no ensino de matemática: Uma experiência com alunos surdos. 2013. 237 f. Tese (Doutorado em Educação Matemática) - Instituto de Geociências e Ciências Exatas, Universidade Estadual Paulista, Rio Claro, 2013.

SALES, E. R; PENTEADO, M. G; MOURA, A. Q. A negociação de sinais em LIBRAS como possibilidade de ensino e aprendizagem de geometria. Bolema, Rio Claro (SP), v. 29, n. 53, p. 1268-1286, 2015.

SILVA, J. S. F. O processo do ensino de matemática para alunos surdos: uma investigação com professores de escolas públicas do município de Sertânia - PE. Monteiro, PB: UEPB, 2017.

SILVA, S. G. de L. Pedagogia surda e ensino da Língua Portuguesa para surdos. In: PERLIN, G.; STUMPF, M. (Org.). Um olhar sobre nós surdos: leituras contemporâneas. Curitiba: CRV, 2012. p. 265-272.

SKLIAR, C. Os Estudos Surdos em Educação: problematizando a normalidade. In:

A surdez: um olhar sobre as diferenças. 3. ed. Porto Alegre: Mediação, 2005. cap. 1, 7-32.

STREIECHEN, E. M; LEMKE, C. K. Análise da produção escrita de surdos alfabetizados com proposta bilíngue: implicações para a prática pedagógica. Belo Horizonte, MG: RBLA, v. 14, n. 4, p. 957-986, 2014.

STREIECHEN, E. M; LEMKE, C. K; OLIVEIRA, J. P; CRUZ, G. C. Pedagogia surda e bilinguismo: pontos e contrapontos na perspectiva de uma educação inclusiva. Maringá, v. 39, n.1, p. 91-101, Jan.-Mar., 2017.

STROBEL, K. L. A visão histórica da in(ex)clusão dos surdos nas escolas. Campinas, SP: ETD, v.7, n.2, p.245-254, 2006.

STUMPF, M. R. Mudanças estruturais para uma Inclusão Ética. In: QUADROS, R. M. de (Org.). Estudos Surdos III. Petrópolis, RJ : Arara Azul, 2008. p. 14-29.

ISSN 2526-2882 


\section{Biografia Resumida}

Regina José Erliton Santos Santana: Licenciado em Matemática pela Universidade Estadual de Santa Cruz (UESC). Mestrando em Educação Matemática pela UESC.

e-mail: erlitonsantana@bol.com.br

Salvador Cardoso Silva Muniz: Licenciado em Matemática pela Universidade Federal do Recôncavo da Bahia. Mestre em Educação Matemática pela Universidade Estadual de Santa Cruz (UESC). Professor da rede na Escola Municipal Reunidas Castro Alves. Membro do Grupo de pesquisa Educação Matemática e Diversidade Cultural (GPEMDiC).

e-mail: umsalvadoor@gmail.com

Jurema Lindote Botelho Peixoto: Licenciada em Matemática pela Universidade Estadual de Santa Cruz. Mestre em Matemática pela Universidade Federal da Bahia (UFBA). Doutora em Difusão do Conhecimento pela Universidade Federal da Bahia (UFBA). Professora Adjunta da Universidade de Santa Cruz (UESC-BA), docente do programa de Pós-Graduação em Educação Matemática da UESC; Líder do grupo de Pesquisa Educação Matemática e Diversidade Cultural- GEPEMDiC. Membro do Grupo de pesquisa Grupo de Estudos e Pesquisas em Educação Inclusiva - GEPEI.

Link

lattes:

http://buscatextual.cnpq.br/buscatextual/visualizacv.do?id=K4 730688T8

e-mail: jurema@uesc.br 